\title{
NUMERICAL SIMULATION OF DPF FILTER FOR SELECTED REGIMES WITH DEPOSITED SOOT PARTICLES
}

\author{
David LÁVIČKA*, Petr KOVAŘíK
}

\begin{abstract}
For the purpose of accumulation of particulate matter from Diesel engine exhaust gas, particle filters are used (referred to as DPF or FAP filters in the automotive industry). However, the cost of these filters is quite high. As the emission limits become stricter, the requirements for PM collection are rising accordingly. Particulate matters are very dangerous for human health and these are not invisible for human eye. They can often cause various diseases of the respiratory tract, even what can cause lung cancer.
\end{abstract}

Performed numerical simulations were used to analyze particle filter behavior under various operating modes. The simulations were especially focused on selected critical states of particle filter, when engine is switched to emergency regime. The aim was to prevent and avoid critical situations due the filter behavior understanding. The numerical simulations were based on experimental analysis of used diesel particle filters.

\section{INTRODUCTION}

One of the goals of this contribution is to provide a numerical simulation of selected processes in the DPF filter. These situations cause the most crucial problems in the operation of a car that is fitted with a diesel engine and a DPF filter. Select processes are nominated using the activities with an experimental analysis of a DPF filter (refer to the text link) and from information from numerical simulations investigated in the DPF filter research (refer to the text links). The analysis of the select situations will assist in understanding the processes in the DPF filter thereby avoiding problems identified in diesel engine cars with a DPF filter.

Another aim of this contribution is to expand the knowledge on the flow field within the DPF filter channel when particles deposit on the walls of the open channels. This part of the contribution compares two important states. The first state represents a new DPF filter or a DPF filter after a proper regeneration. In this case, no soot particles are found in the channels. The other state represents a DPF filter that is full of deposited soot particles on the walls of the channels, making the intake area of the open channels considerably reduced in comparison to the first state [3].

\footnotetext{
- David Lávička, Západočeská univerzita v Plzni, Univerzitní 8, 30614 Plzeň, Czech Republic, dlavicka@ntc.zcu.cz

Petr Kovařík, Západočeská univerzita v Plzni, Univerzitní 8, 30614 Plzeň, Czech Republic, kovarikp@ntc.zcu.cz
}

This is an Open Access article distributed under the terms of the Creative Commons Attribution License 2.0, which permits unrestricted use, distribution, and reproduction in any medium, provided the original work is properly cited. 


\section{GEOMETRY AND BOUNDARY CONDITIONS}

The computational model (see Figure 1) is divided into five sections: inlet, inlet/transition, deposit, outlet/transition, and outlet. The intake and outlet transition sections consist of individual channels that represent the chessboard distribution of open and closed channels. The computational model was prepared in GAMBIT 2.4.6 preprocessing software. A standard mapped hexagonal mesh is used for the numerical simulation. The capacity of the computational mesh per segment is 1.2 million (see Figure 1).

The inlet boundary condition was defined as "mass flow inlet" to enter the mass flow. The value was calculated using the ratio between the segment area and the area of the DPF filter. Mutual comparison of filters is generated for individual operating conditions with a mass flow of $180 \mathrm{~g} / \mathrm{s}$ (only calculated mass is used in the segment). Air at $20^{\circ} \mathrm{C}$ offers properties nearly identical to those of exhaust gas; therefore, it was selected as the flow medium.

The outlet transition section is identical to the inlet transition section; however, the arrangement of the open and closed channels is the opposite to the inlet transition section. The outlet boundary condition was defined as "pressure outlet". Individual boundary conditions are described in Figure 1.

The numerical simulation was performed using the ANSYS-FLUENT 13 commercial software.

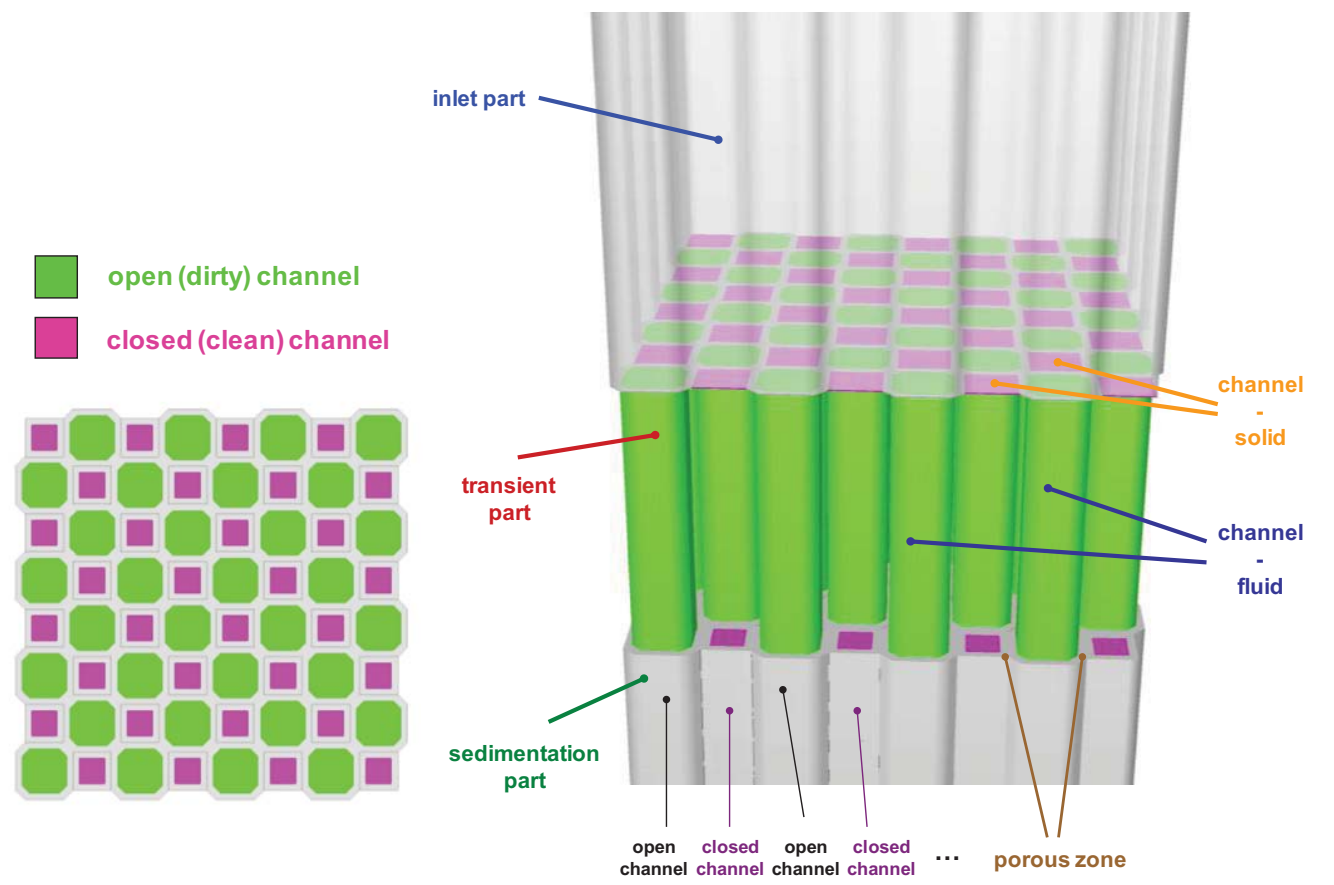

Figure 1: Computational model showing individual sections and boundary conditions

\section{Select SituAtions IN THE DPF FILTER}

This paper looks into five basic tasks that have been processed and evaluated in detail. The purpose of these suggested states is to describe the basic principle of DPF filter behavior; the states combine in reality and, typically, several states occur at the same time. The individual modes provide better and clearer illustration of the effects of the select situations occurring in the DPF filter. Individual situations are shown in Figure 2. 
The select situations are processed at a mass flow of $180 \mathrm{~g} / \mathrm{s}$ and for $1.1 \mathrm{~mm}$ channel size in the DPF filter.

The "basic" variant describes the basic variant when the DPF filter channels are free of particle deposits: they are empty. This state represents a brand new DPF filter or the state after a proper regeneration.

The "center-full" and "center-empty" variants describe two mutually opposed situations. In the former case, the blocked cells concentrate in the middle of the subject segment while in the latter; they are located on the edge of the segment. Blocked cells show higher resistance, i.e. their pressure loss of exhaust gas is higher.

The "1ch-position 44" and "2ch-position 44-55" variants represent a case of an inclusion present in the channel $[1,3]$ that limits or even blocks the passage of exhaust gas through one or more channels. The "1ch-position 44 " is the variant with an inclusion in a single channel at position $\mathrm{x} 4 \mathrm{y} 4$; the "2ch-position 44-55" variant shows two inclusions in positions $x 4 y 4$ and $x 5 y 5$ in two channels.

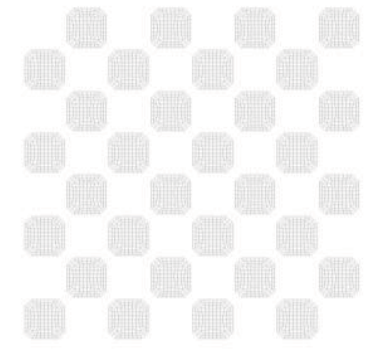

basic

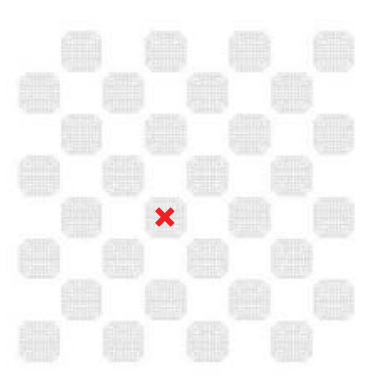

one channel

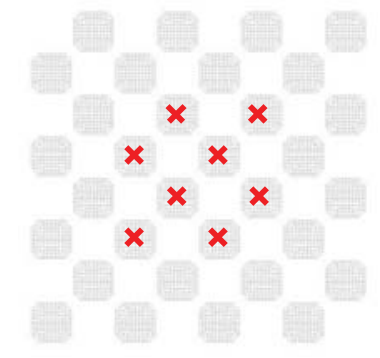

center - ful

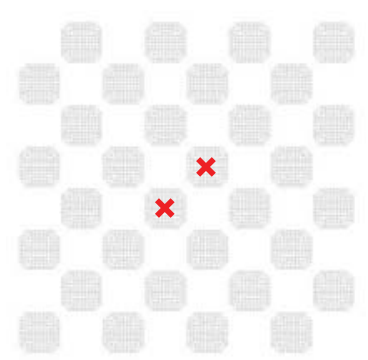

two channels

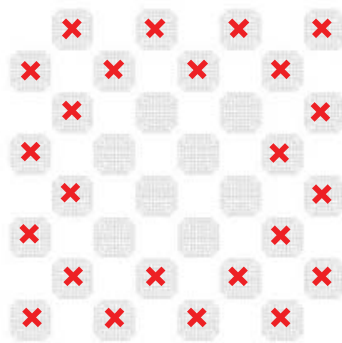

center - empty

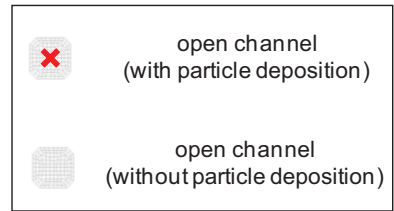

Figure 2: List of select situations in the DPF filter

\section{RESULTS FOR SELECT SITUATIONS IN THE DPF FILTER}

Figure 3 shows the flow field of velocity $v_{z}$ in the direction of axis $z$ in plane $z=100 \mathrm{~mm}$. The plane is located approximately in the center of the DPF filter. The results presented below suggest considerable increase of velocity $v_{z}$ in the "center-full" and "center-empty" variants as opposed to the "basic" variant. The considerable increase of velocity $v_{z}$ is caused by the reduction of the flow section, with the exhaust gas flowing only through the open channels where no pressure resistance exists. Higher velocities occurred in the closed channels as well. Minor increase of velocity $v_{z}$ is also seen in the "1ch-position 44" and "2ch-position 44-55" variants; however, it is not quite remarkable as the resistance was entered at a smaller flow area. The situations suggest that the DPF filter is highly sensitive to channels with deposited soot particles, which generates resistance to the passage of exhaust gas. 
In the case of showing the flow field in the components of velocity $v_{X}$, the most prominent effects are seen in the "center-full" and "center-empty" variants where considerable irregularity of exhaust gas passage in the segment area. These flow fields are also evaluated at axis $z=100 \mathrm{~mm}$. In the case of variants " $1 \mathrm{ch}$-position 44 " and "2chposition 44-55", minor irregularity of the flow field occurs in the area of the DPF filter. This confirms the conclusion mentioned above of the DPF filter being highly sensitive to channels with deposited soot particles, which generates resistance to the passage of exhaust gas.

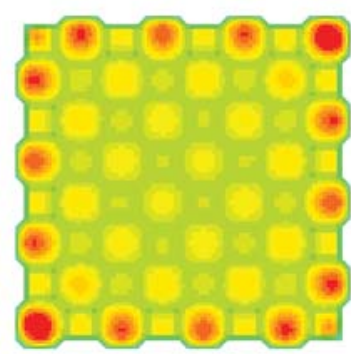

basic

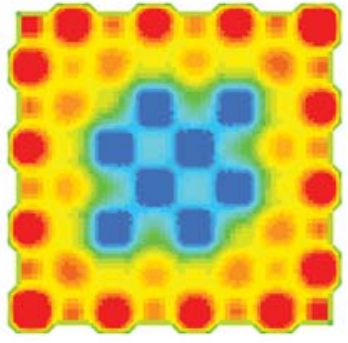

center - full

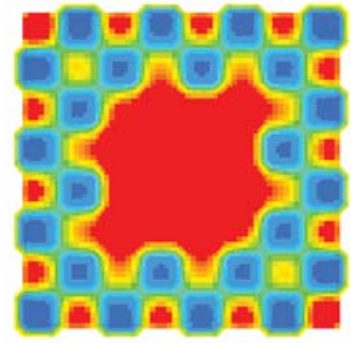

center - empty velocity $v_{z}$ $[\mathrm{m} / \mathrm{s}]$

$2.50 \mathrm{e}+01$

$2.38 \mathrm{e}+01$

$2.25 \mathrm{e}+01$

$2.13 \mathrm{e}+01$

$2.00 \mathrm{e}+01$

$1.88 \mathrm{e}+01$

$1.75 \mathrm{e}+01$

$.63 \mathrm{e}+01$

$1.38 \mathrm{e}+01$

$1.25 \mathrm{e}+01$

$1.13 \mathrm{e}+01$

$1.00 \mathrm{e}+01$

$7.50 \mathrm{e}+00$

$6.25 \mathrm{e}+00$

$5.00 \mathrm{e}+00$

$3.75 e+00$

$2.50 \mathrm{e}+00$

$1.25 e+00$

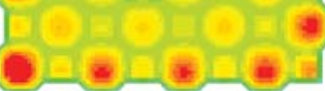

one channel

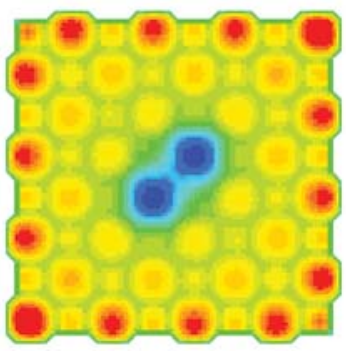

two channels

Figure 3: Distribution of the flow field of velocity $v_{z}$ at $z=100 \mathrm{~mm}$

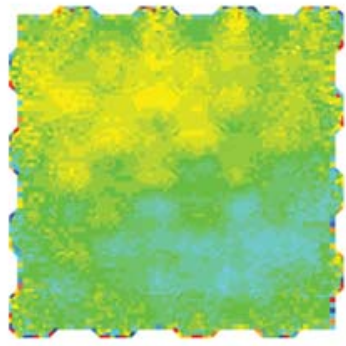

basic

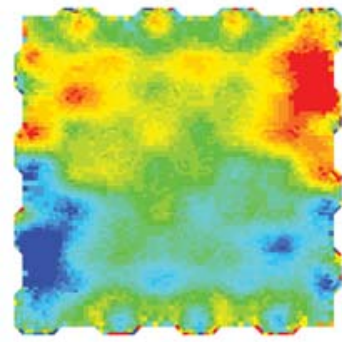

center - full

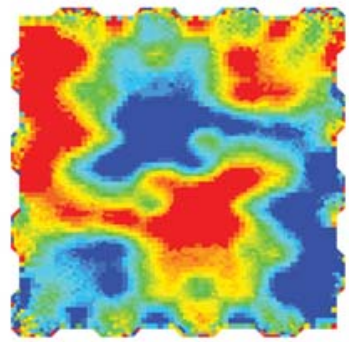

center - empty velocity $\mathbf{v}_{\mathrm{X}}$ $[\mathrm{m} / \mathrm{s}]$

$5.00 \mathrm{e}-04$

$4.50 \mathrm{e}-04$

$4.00 \mathrm{e}-04$

$3.50 \mathrm{e}-04$

3.00e-04

$2.50 \mathrm{e}-04$

$2.00 \mathrm{e}-04$

$1.50 \mathrm{e}-04$

$1.00 \mathrm{e}-04$

$5.00 \mathrm{e}-05$

$0.00 \mathrm{e}+00$

$-5.00 \mathrm{e}-05$

$-1.00 \mathrm{e}-04$

$-1.50 \mathrm{e}-04$

$-2.00 \mathrm{e}-04$

$-2.50 \mathrm{e}-04$

$-3.00 \mathrm{e}-04$

$-3.50 \mathrm{e}-04$

$-4.00 \mathrm{e}-04$

$-4.50 \mathrm{e}-04$

$-5.00 \mathrm{e}-04$

one channel

two channels

Figure 4: Distribution of the flow field of velocity $v_{x}$ at $z=100 \mathrm{~mm}$ 
Results shown in Figures 6, 7, and 8 provide a comparison of characteristic parameters (e.g. static pressure, individual velocity components, etc.) for filter with channel dimension $1.1 \mathrm{~mm}$ while the DPF filter is clogged with soot particles. Each chart compares the state of the flow field for each select situation (see Figure 2) along the entire channel. The evaluation used selected open (left charts) and closed channels (right charts) that are shown Figure 5. The dot color shows the evaluation channel and corresponds to the curve color in the chart.

Note that the flow direction in the charts is from right to left! The inlet is located at $0.174 \mathrm{~mm}$; the outlet from the DPF filter is located at position $0 \mathrm{~mm}$. These selected situations were simulates in ANSYS-FLUENT 13 commercial software. MATLAB software was used for the evaluation and preparation of charts showing the flow field behavior in individual channels.

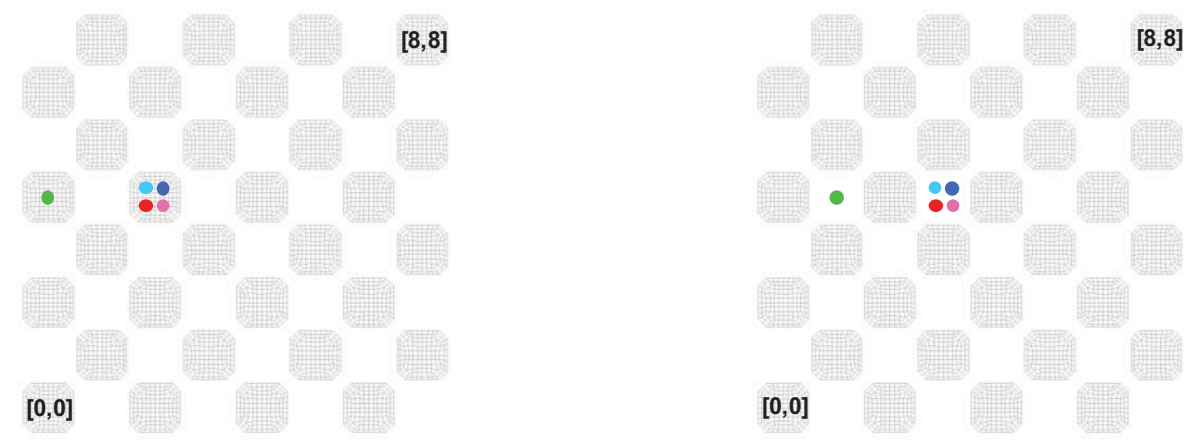

Figure 5: List of evaluated channels for each variant

\section{Static Pressure}

The charts in Figure 6 compare the static pressure along individual channels for all the variants described in Chapter 3. The green line of the "center-empty" variant shows higher static pressure in the DPF filter channel. This arrangement indicates the highest resistance to exhaust gas passage through the DPF filter segment. Compared to the "basic" variant, other select situations do not show considerable increase of pressure loss. Situations marked "1ch-position 44" and "2ch-position 44-55" show development that is nearly identical to the "basic" variant".
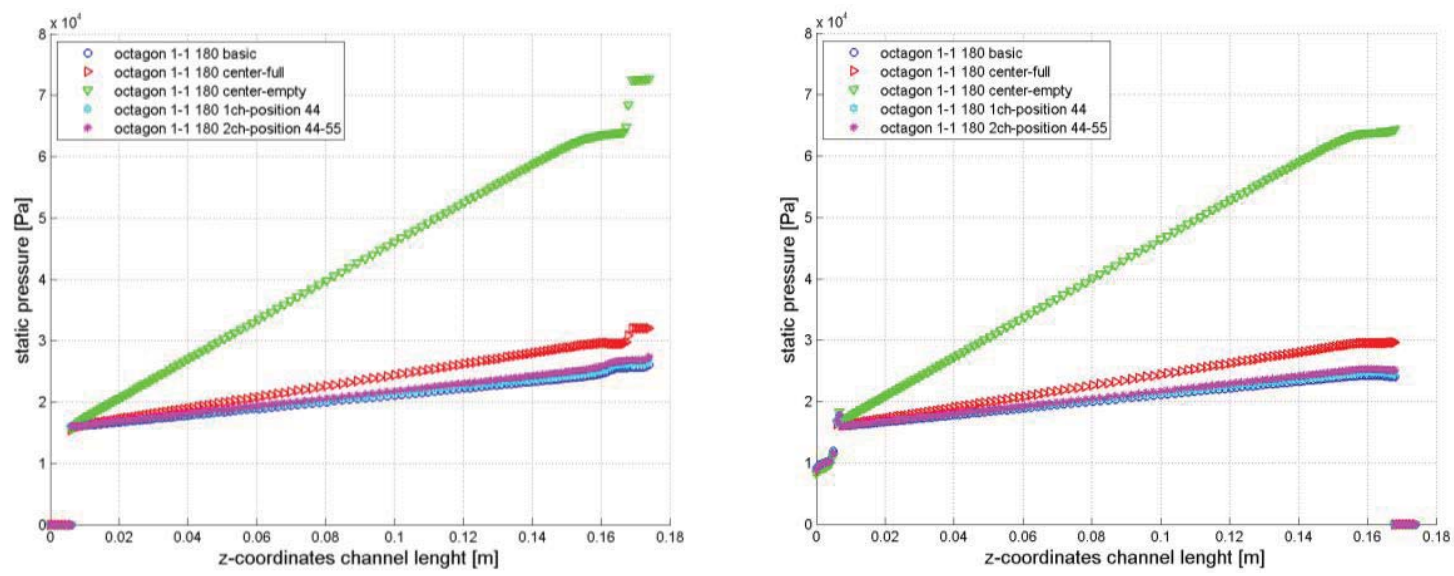

Figure 6: Static pressure development in the open and closed channel 


\section{VELOCITY V Z}

Figure 7 compares the axial components of velocity $v_{z}$. The cause of velocity drop in the open channel in the "center-empty" and "center-full" variants is the location of the channel in an area where several channels with high resistance are present. The "centerempty" variant in the closed channel (the chart on the right) shows higher velocity $v_{z}$ as the exhaust gas flow divides into a smaller number of closed channels. This statement is based on the list of select situations in the DPF filter in Figure 2. Variants "1ch-position 44 " and "2ch-position 44-55" indicate influence to velocity $v_{z}$ because the channels of interest are located near an inclusion (a blocked channel).
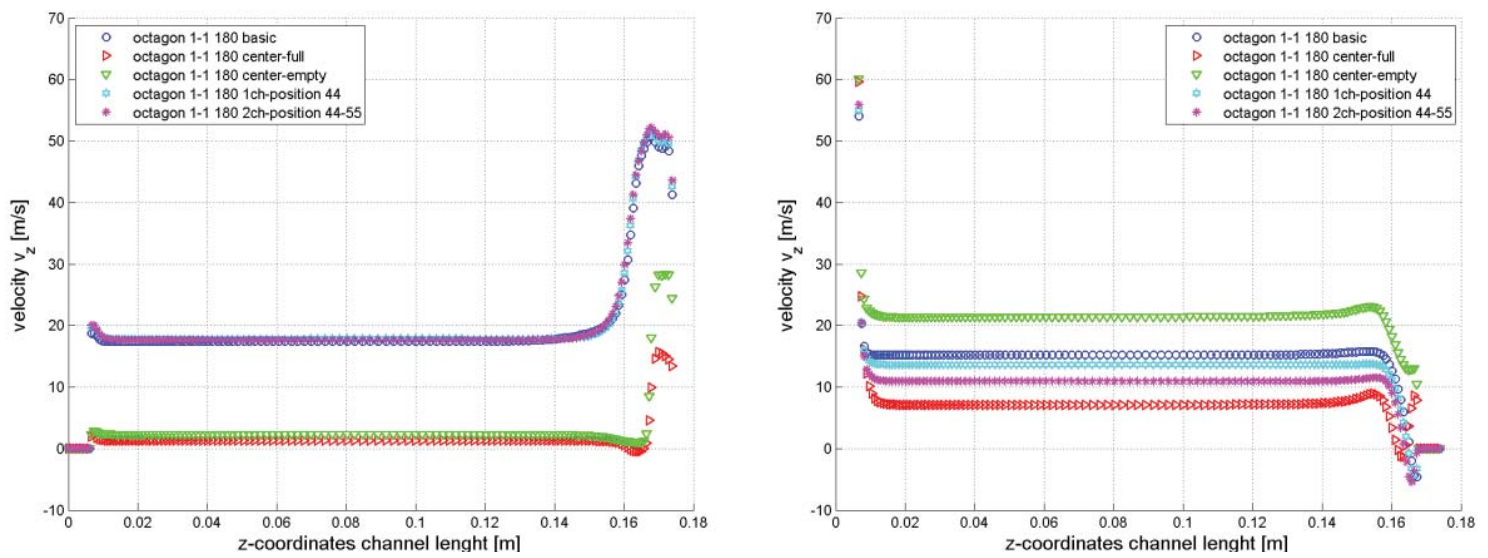

Figure 7: Development of velocity $v_{Z}$ in an open and closed channel

\section{VELOCITY V $\mathbf{X}$}

Figure 8 shows the development of the components of velocity $v_{X}$ in the open and closed channels of the DPF filter. The evaluated results suggest that the velocities in $v_{X}$ components differ proportionally to the number of high resistance channels present in the area. If several high resistance channels exist in the area, the corresponding velocity increases in the component. Similar behavior was seen also in the $v_{Y}$ velocity component.
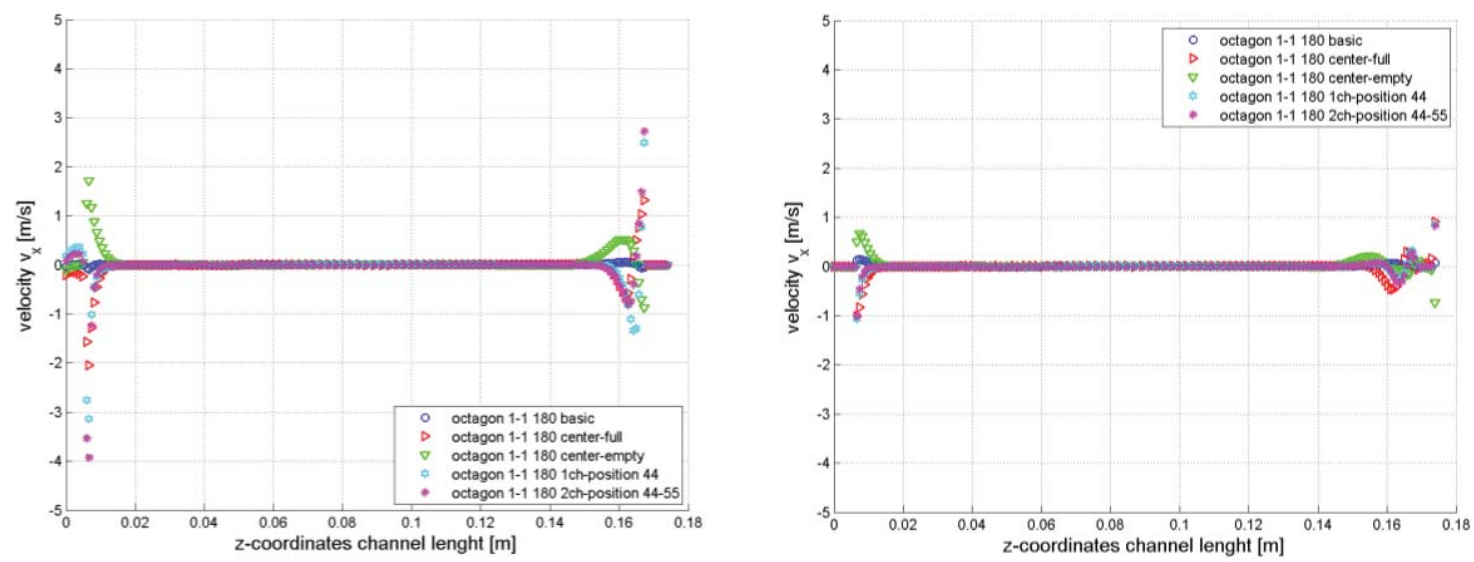

Figure 8: Development of velocity $v_{X}$ in an open and closed channel 


\section{TOPIC OF CHANNEL NARROWING BY DEPOSITION OF PARTICLES IN THE DPF FILTER}

The topic of dynamic narrowing of channels in relation to the amount of particle matter deposit was planned for inclusion of the UDF program in the past years of project investigation. However, the unsuitability and complexity of the solution showed over time. The complexity of the model is primarily related to the octagonal shape of the channel; dynamic change of the channel shape is very complicated. Another problem is the growing requirement for computer time, as the computational mesh of the individual DPF filter channels would require considerable level of additional detail. A more detailed computational mesh would lead to major extension of the calculation times and to a more complicated assessment of the results. In order to curb the reasons above, a simplified version of the project was implemented with a segment consisting of the smaller channels only to replace a specific state of the DPF filter full of soot particles. This case uses a situation with the channel inlet area lower by $50 \%$. In practice, the reduction of the channel inlet area may amount to as much as $70 \%$. The photograph of a DPF filter with square-type channels in Figure 2 illustrates the reduction of the channel flow area.

The initial variant of the DPF filter was a unit with $1.5 \mathrm{~mm}$ octagonal channels, currently the most popular choice of car manufacturers. The state represents a new DPF filter or a filter that has regenerated by "burning" the soot particles deposited in the open channels of the DPF filter. The other state represents a DPF filter filled with soot particles with the inlet area reduced by $50 \%$. The state approximately corresponds to a DPF filter with $1.1 \mathrm{~mm}$ channel size. The two states, too, were calculated using numerical simulation in the ANSYS-FLUENT 13 commercial software. MATLAB software was used for the evaluation and preparation of charts showing the flow field behavior in individual channels.

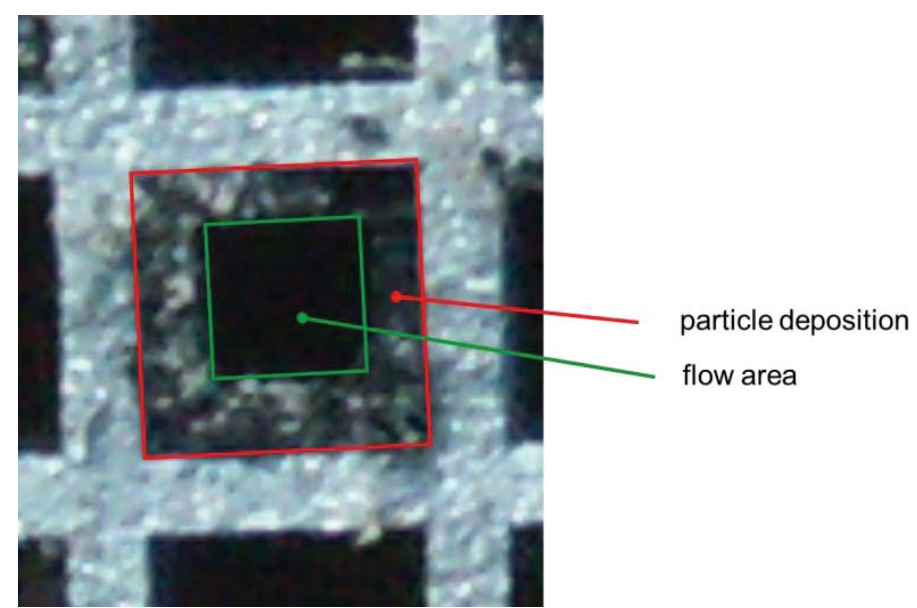

Figure 9: Reduction of flow area by particle deposition in a square-shaped channel

\section{ChARACTERISTICS OF A FLOW FIELD AFFECTED BY PARTICLE DEPOSIT}

The results provide a comparison of characteristic parameters (e.g. static pressure, individual velocity components, etc.) for filter with DPF filter channel dimension $1.1 \mathrm{~mm}$ and $1.5 \mathrm{~mm}$. Channel size $1.5 \mathrm{~mm}$ corresponds to a DPF filter in the initial, empty state or after regeneration when the deposited (trapped) soot particles have burned. The opposite situation corresponds to $1.1 \mathrm{~mm}$ channels where the DPF filter is filled with soot particles. 


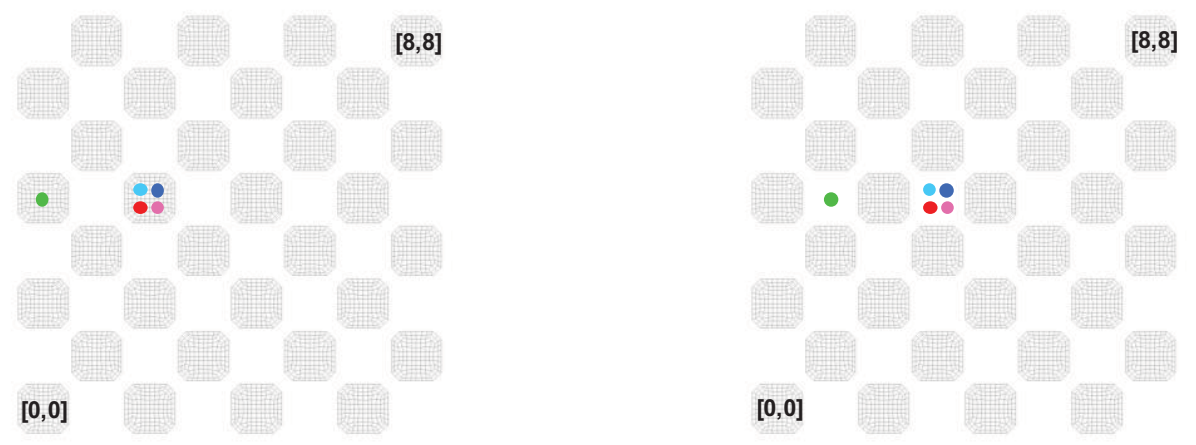

Figure 10: List of evaluated channels for each variant

Each of the charts compares the state for two channel sizes and two mass flow rates: $80 \mathrm{~g} / \mathrm{s}$ and $180 \mathrm{~g} / \mathrm{s}$. $180 \mathrm{~g} / \mathrm{s}$ represents the mass flow at higher engine speeds (the flow rate is equal to maximum engine speed).

Note that the flow direction in the charts is from right to left! The inlet is located at $0.174 \mathrm{~mm}$; the outlet from the DPF filter is located at position $0 \mathrm{~mm}$.

\section{Static Pressure}

The charts in Figure 11 compare the static pressure along individual channels for all the variants described above. A critical result is the extreme growth of static pressure (up to four times higher) in the variant with $1.1 \mathrm{~mm}$ channel size and $180 \mathrm{~g} / \mathrm{s}$ flow rate at Figure 11. The other cases exhibit "typical" development. The fact explains many problems that have been observed in situations with extreme clogging of the DPF filter channels and an incorrect regeneration procedure. Incorrect regeneration procedure of the DPF filter leads to less than perfect burn of the soot particles than prevent exhaust gas from passing through the channels. Such situations may lead to generation of inclusions and seal the channel completely. This type of phenomenon is presented in the preceding section of the paper. These situations very often lead to the engine switching to the emergency mode due to major pressure loss at the DPF filter.
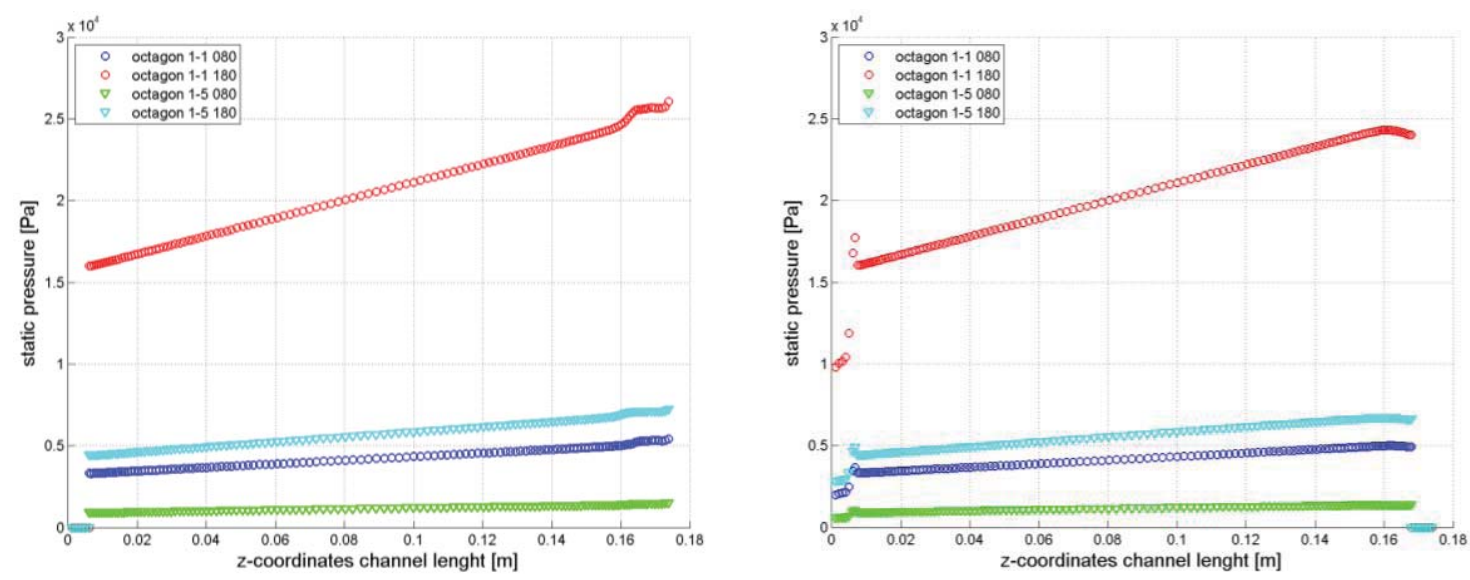

Figure 11: pressure development in the open and closed channel

\section{VELOCITY $\mathbf{V}_{\mathbf{Z}}$}

Similar situation is described by other charts in Figure 12 that show the development of the $v_{z}$ velocity component. In the case of channel size $1.1 \mathrm{~mm}$ and flow 
rate $180 \mathrm{~g} / \mathrm{s}$, velocity growth is remarkable both in the open and closed channels of the DPF filter. In the open channel, the velocity of exhaust gas at the inlet into the DPF filter nearly triples to almost $140 \mathrm{~m} / \mathrm{s}$. The development seen in the other variants is as predicted. The growth in velocity $v_{z}$ exhaust gas shows at the outlet from the closed channels is not as big as in the open channel inlet. Exhaust gas velocity at the outlet rose from $30 \mathrm{~m} / \mathrm{s}$ to approximately $50 \mathrm{~m} / \mathrm{s}$.
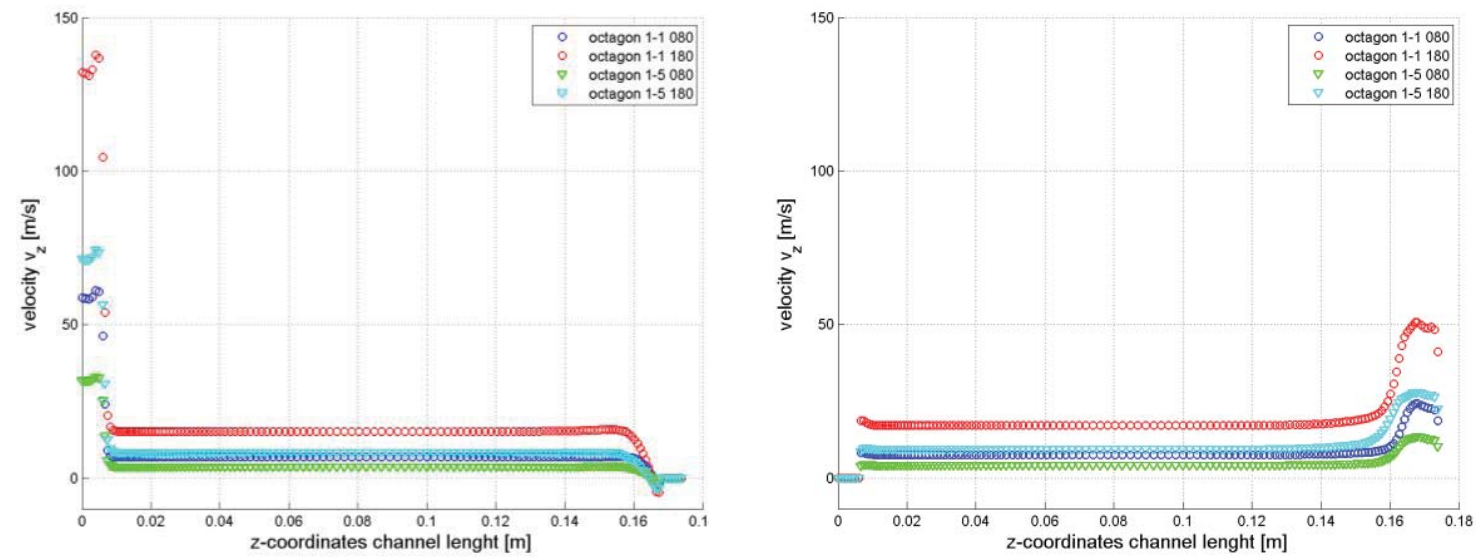

Figure 12: Development of velocity $v_{z}$ in an open and closed channel

\section{VELOCITY $\mathbf{V}_{\mathbf{X}}$}

These charts show the development of velocity $v_{X}$. The higher the inlet velocity $v_{Z}$ the higher velocity $v_{x}$ as the transfer flow is higher between the channels across the porous channel walls in the DPF filter. Exhaust gas transfers from an open channel (a channel that is open at the inlet and closed at the outlet) to a closed channel (a channel that is closed at the inlet and opens at the outlet).
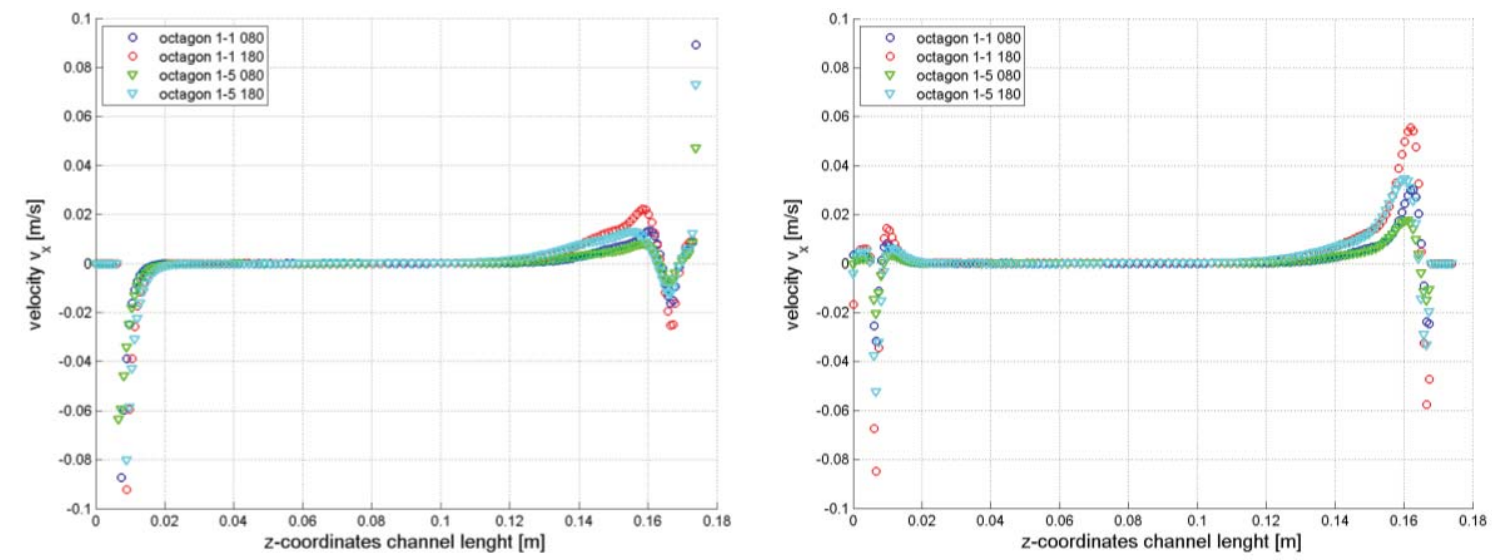

Figure 13: Development of velocity $v_{X}$ in an open and closed channel

\section{CONCLUSION}

The assessed results of the selected situations in the DPF filter indicate that the DPF filter is extremely sensitive to channels with deposits of soot particles that generate resistance to exhaust gas passage. All channels that generate considerable resistance and even channels blocked with inclusions lead to irregularity of the flow field in the DPF filter. 
Should a DPF filter contain a higher number of such channels in combination with an improper regeneration process, the filter will most likely cause major problems in the operation of the vehicle.

The second part of the contribution describes the situation with channel area reduction: what happens inside the DPF filter, when it becomes blocked with a higher number of particulate matters deposited on the channel walls. The results describing channel reduction from $1.5 \mathrm{~mm}$ to $1.1 \mathrm{~mm}$ clearly suggest that reduction in cross-section leads to abrupt increase of pressure resistance in the filter and to considerably higher velocity $v_{Z}$ of the exhaust gas in the inlet area. The higher velocity $v_{z}$ subsequently increases other velocity components also; they have negative effects to regular distribution of the flow field in the filter.

An important conclusion of the text affects the operation of a diesel engine car with a DPF filter. Any such vehicle is extremely sensitive to any improper regeneration of the DPF filter because it may lead to major complications in the use of the car. The risk of improper regeneration occurs primarily in urban traffic as the engine starts up constantly and the car moves slowly in traffic congestions. Sporadic trips on the highway or on a principal road may prevent the occurrence of such critical situations and problems with improper regeneration of the DPF filter. The latter situations lead to significantly better burn of the soot particles deposited on the walls of the DPF filter: such regeneration may be called proper and successful.

\section{ACKNOWLEDGEMENTS}

This paper is based upon work sponsored by the Ministry of Education, Youth and Sport of the Czech Republic under research and development project 1M06031. We would also like to thank the MetaCentrum project for their Linux PC cluster computational support.

\section{RefEREnCES}

[1] Lavicka David : Analýza usazování částic v DPF filtru pomocí numerických a experimentálních metod. PhD thesis, ZČU v Plzni, září 2008, Plzeň.

[2] Lavicka D.; Knourek J.; Polansky J. : CFD Simulation in the Individual Channels of the Particle Filter. In 3.rd European Automotive CFD Conference, Frankfurt, Germany, 5-6 july 2007. ISBN 0-9719532-1-x.

[3] Lavicka, David; Knourek, Jindrich. Numerical simulation with particle deposition on channel walls in the DPF filter. In Experimental Fluid Mechanics 2010. Liberec:Technical University, 2010, s. 344-353.

[4] ANSYS, Inc., 2011. ANSYS FLUENT Theory Guide, Release 13.0, Nov. 2010.

[5] Fabio Sbrizzai, Paolo Faraldi and Alfredo Soldati : Appraisal of three-dimensional numerical simulation for sub-micron particle deposition in a micro-porous ceramic filter. In Chemical Engineering Science, Volume 60, Issue 23, December 2005, Pages 6551-6563.

[6] Lamacchia, S.; Pidria, M.F.; Faraldi, P.; Corrias, S.: Detection of ash and particulate distribution in diesel particulate filters through $X$-ray computed tomography. In Centro Ricerche FIAT S.C.p.A., Italy. 